\section{B A Institute of \\ YK Business Administration \\ 秉 \\ Karachi \\ Leadership and Ideas for Tomorrow}

Article 4

Volume 15 Issue 2 July-December 2020

$1-15-2021$

\title{
Speculation and returns' volatility: Evidence from Pakistan Mercantile Exchange
}

Falik Shear

National Textile University, Pakistan

Follow this and additional works at: https://ir.iba.edu.pk/businessreview

Part of the Finance Commons

(c) (i)

This work is licensed under a Creative Commons Attribution 4.0 International License.

\section{Recommended Citation}

Shear, F. (2021). Speculation and returns' volatility: Evidence from Pakistan Mercantile Exchange. Business Review, 15(2), 75-85. Retrieved from https://doi.org/10.54784/1990-6587.1061

This article is brought to you by iRepository for open access under the Creative Commons Attribution 4.0 License and is available at https://ir.iba.edu.pk/businessreview/vol15/iss2/4. For more information, please contact irepository@iba.edu.pk. 


\title{
Speculation and returns' volatility: Evidence from Pakistan Mercantile Exchange
}

\author{
Falik Shear
}

\begin{abstract}
The debate about the role of speculators in commodity markets has been intensified after the financialization. The current study augments the empirical evidence related to speculators and their impact on volatility of commodity markets. In doing so, the study uses daily data between 12 th November 2009 to 30th April 2020 for oil and gold future contracts from Pakistan Mercantile Exchange. The findings suggest that speculative activity positively and significantly affects the returns' volatility. These findings support the destabilizing hypothesis, which argues that speculators create distortions in commodity markets. The findings have important implication for market participants (e.g., absence of welfare gain for hedgers) and regulators.
\end{abstract}

Keywords Speculation · Volatility · Gold future contracts · Oil future contracts · EGARCH · PMEX

\section{Introduction}

The role of speculators in commodity markets has been increasingly debated during the past decade. This debate is primarily ignited by the financialization of commodity markets. Bohl et al (2018) note "a sharp rise in the popularity of commodity investing has triggered a large inflow of investment capital into commodity futures markets. This phenomenon, known as the "financialization" of commodity markets, has encouraged an extensive debate".

Two contrary hypotheses are prevailing with respect to role of speculators in commodity markets i.e., stabilizing, and destabilizing hypotheses. Proponents of stabilizing hypothesis argue that profitable speculations can filter out the noise or irrational traders and can stabilize the market by buying, during lower, and selling, during higher prices periods (Brunetti et al 2011). This argument is supported by empirical findings as well. For instance, Bohl and Sulewski (2019)

Falik Shear

National Textile University-Pakistan

E-mail: falik.shear@ntu.edu.pk

(C)Shear, F. 2020 
find that speculators reduce the market volatility. Some studies find no effect of speculators. For example, Irwin and Yoshimaru (1999) find no significant influence of speculators on price volatility during pre-financialization period. Bohl and Stephan (2012) find similar results for post-financialization period. Advocates of destabilizing effect, prominently led by Michael W. Masters, argue that massive buying pressure due to financialization has led to a bubble in commodity prices by moving prices far away from fundamentals. In this lieu, Daigler and Wiley (1999) find that general public increase volatility in future markets. They categorize general public as uninformed traders who are unable to "differentiate liquidity demand from fundamental value" (Daigler and Wiley 1999). During post-financialization Du et al (2011) find positive influence of speculative activity on future price volatility. The present article is an effort to augment the empirical evidence by exploring impact of speculative activities on conditional volatility of commodity future returns.

All recent studies on speculation-volatility relationship focus on developed countries like United States and China. To the best of the author's knowledge, no study focuses on this relationship for a developing country like Pakistan. Thus, this article aims to extend literature by tapping an untapped commodity market. Moreover, studies focused on the US market generally use data from Commodity Future Trading Commission (CFTC) databases. However, this data is not available for other countries. The current study uses data of energy and metal commodities i.e., oil and gold from Pakistan Mercantile Exchange (PMEX) to study the relationship between speculative activity and conditional volatility of returns.

PMEX was formulated in 2002 under regulations of the Securities and Exchange Commission of Pakistan (SECP) as a first commodity trading platform of the country. It started its operation in May 2007 and currently offers a wide range of future contracts on different national and international commodities. Currently PMEX is providing future contracts trading options in Metal, Energy, Agriculture and Equity indexes. On 28th May 2020, daily trading volume amounted to Rs. 6.2 billion.

Findings of the current study have twofold implications. On one hand it extends the current literature, while on the other hand it will be helpful for market participants and regulators of PMEX. If the stabilization hypothesis is proven in the study it implies efficiency and stability of PMEX, thus, minimizing the need for corrective actions by regulators. Moreover, investors can expect more stable returns from this market. Contrarily, proving of destabilizing hypothesis will require regulators to intervene/monitor the role of speculators so that possible distortions in the market can be avoided. Additionally, investors can expect more risky returns from this volatile market.

Remainder of the paper is organized as follows: section 2 reviews the relevant literature and identifies the gaps. Section 3 describes the methodology being used in the study. Subsequent section elaborates results and discussion, and final section concludes the study. 


\section{Literature review}

The commodity markets are generally characterized by two types of traders i.e., hedgers and speculators. Commodity Futures Trading Commission (CFTC) of the US defines that a hedger is "a trader who enters into positions in a futures market opposite to positions held in the cash market to minimize the risk of financial loss from an adverse price change or who purchases or sells futures as a temporary substitute for a cash transaction that will occur later." A speculator is defined as "a trader who does not hedge, but who trades with the objective of achieving profits through the successful anticipation of price movements." The basic definition of speculators increases their vulnerability to the argument that they admire/increase volatility in commodity markets. This argument was further strengthened after the increased involvement of index traders (a phenomenon known as "financialization") in the commodity markets. Consequently, an extensive number of empirical studies focus on the role of speculators in commodity markets.

For instance, Bohl and Sulewski (2019) study the impact of speculators on commodity markets by using data (from 2006 to 2017) for five agriculture commodities from the US market. The authors use the GARCH model to find out whether speculators destabilize the commodity market or not. Their findings highlight that speculators do not destabilize the market. Instead, authors find that speculators reduce volatility in the market. Kim (2015) highlights the relationship between speculation and future market volatility for the US commodity market. The author uses data from October 1992 to July 2012 for 14 actively traded future contracts. The author uses GARCH model to assess the impact of speculative activities on conditional volatility. The findings suggest that speculation has no impact on prices. Contrarily, speculators contribute to reduction of price volatility.

Huchet and Fam (2016) explore the relationship between speculation and returns of eight commodities i.e., cocoa, coffee, corn, rice, soybean, sugar, and wheat. By using weekly data from 1998 to 2013, authors validate the hypothesis that speculators have positive impact on future market returns. Bosch and Pradkhan (2015) also study the above-mentioned relationship for four precious metals, which are gold, palladium, platinum, and silver. Their sample period includes daily data from June 13, 2006 to December 31, 2013. The authors use GARCH model to study the impact of speculation on returns volatility. The authors are unable to rule out the impact of speculation or return volatility for long horizon analysis. However, they find contrary evidence for short horizon analysis.

The prior mentioned studies focus on speculative behavior in the US market, and generally use data from Commodity Future Trading Commission (CFTC). CFTC divides weekly trading data of US commodity investors into speculative or hedging activities. However, this database is only available for the US. This research uses market activity-based data i.e. trading volume and open interest to study the behavior of Pakistan's commodity market.

Recent growth of Chinese commodity market has grabbed the attention of many researchers. For example, recently Wellenreuther and Voelzke (2019) study 
the relationship between speculation and return volatility by using data of four frequently traded commodities of Chinese commodity market. The authors use time varying models to study the said relationship for the period March 27, 2009 to June 20, 2018. The authors use speculative ratio of Garcia et al (1986) as proxy for speculation activity. Findings suggest little to no impact of speculative activity on return volatility.

Similarly, Bohl et al (2018) explore the relationship between speculation activity on conditional volatility of eight future contracts of Chinese commodity market. They use data from 2003 to 2017 and apply GARCH and VAR models to study impact of speculators on return volatility. Their findings suggest that speculation activity positively and significantly impacts the conditional volatility of seven commodity returns. However, the results of these studies might not be applicable to growing markets like Pakistan.

Few studies explore the derivative market related to Pakistan e.g. Shear and Butt (2017), however, these authors focus on Sovereign Credit Default Swaps (SCDS). So far, no study encompasses the speculative behavior and its impact on Pakistan's commodity market. This study focuses on fulfilling this gap. The study of the Pakistani market can be interesting for local and international investors as it can provide new insights and investment opportunities to both these investors.

\section{Methodology}

\subsection{Data}

Data has been collected for two major sectors of commodities that are being traded in PMEX. The first one is the energy sector. From this sector Crude oil future contracts are used. The sample includes daily data from 2nd June 2011 to 30th April 2020 i.e., 2299 observations. The second sector is the metal sector. For this sector, 1 Ounce Gold contracts are used. This sample includes daily data from 12th November 2009 to 30th April 2020 i.e., 2702 observations. Returns are calculated by using the following formula:

$$
\text { Ret }=\left(\operatorname{Ln}\left(C S_{t}\right)-\operatorname{Ln}\left(P S_{t}\right)\right) * 100
$$

where Ret $=$ returns, $L n=$ Natural logarithmic, $C S=$ Current Settlement price at time period $t, P S=$ Previous Settlement price at time period $t$.

To measure the speculative activity speculation ratio proposed by Garcia et al (1986) is used. Previous researchers e.g. Wellenreuther and Voelzke (2019) have also used this ratio as a proxy for speculation activity. The ratio is calculated by using the following formula:

$$
S p r_{t}=\frac{T V_{t}}{O I_{t}}
$$

where $S p r$ is speculation ratio on a given day, $T V$ is trading volume and $O I$ is open interest. Speculation ratio basically measures relative dominance of speculators over hedgers in the market. Higher values of Speculation ratio imply 
higher speculation activity while its lower values indicate lower speculation activity in comparison with hedging. This ratio mirrors the underlying assumption that hedgers hold positions for longer time periods and roll over their trading position in market, while speculators prefer short horizons and trade on intraday basis and thus, influence daily trading volume. On the other hand hedgers increase/decrease daily open interest (number of contracts remain unsettled at the end of day) (Wellenreuther and Voelzke 2019). The underlying assumption of speculation ratio i.e. hedgers hold their positions for longer time periods is well supported by empirical evidence as well (Ederington and Lee 2002).

\subsection{Model}

The Autoregressive Conditional Heteroscedasticity (ARCH) model of Engle (1982) and Generalized ARCH (GARCH) by Bollerslev (1986) have been extensively used in literature to model volatility. However, the ARCH/GARCH models do not accommodate impact of negative or positive shocks in volatility (Asteriou and Hall 2011), which means these models do not account for asymmetries in data series. Thus, Nelson (1991) introduced Exponential GARCH (EGARCH) to capture asymmetries in terms of positive and negative shocks. This study uses EGARCH $(1,1)$ model to explore the impact of speculation activity on conditional volatility of returns. The mean equation of the model is as under:

$$
\operatorname{Ret}_{t}=a_{0}+a_{1} \text { Ret }_{t-1}+a_{2} R K S E+\epsilon_{t}
$$

where Ret is return on future contract on time $t, R K S E$ is return of Karachi Stock Exchange 100-index, $a$ is constant and $\epsilon$ is error term.

The variance equation is as under:

$$
\log \left(h_{t}\right)=\gamma_{0}+\Sigma_{j=1}^{P}+\gamma_{j} \frac{\left|\epsilon_{t-1}\right|+\gamma_{j} \epsilon_{t-1}}{\sqrt{h_{t-j}}}+\Sigma_{k=1}^{L} \delta_{k} h_{t-1}+\beta_{1} \text { Spr }_{t}
$$

Equation (4) models the relationship between speculation ratio and conditional variance while accommodating for leverage effect. When $\epsilon_{t-1}$ is positive (good news) the total effect of $\epsilon_{t-1}$ is $\left(1+\gamma_{j}\right)\left|\epsilon_{t-1}\right|$. While in case of bad news i.e., $\epsilon_{t-1}$ is negative, the total effect of $\epsilon_{t-1}$ is $\left(1-\gamma_{j}\right)\left|\epsilon_{t-1}\right|$. The left hand side of equation 4 guarantees variance estimates to be non-negative (Asteriou and Hall 2011). $\beta$ measures the impact of speculation activity (proxied by speculation ratio) on conditional variance. A positive value of $\beta$ implies that speculation activity increases the return volatility, or we can say speculative activity destabilizes the future market. A negative value of $\beta$ implies that speculation activity decreases returns volatility. In other words, speculative activity stabilizes the market in accordance with the stabilizing hypothesis.

\section{Results and discussion}

Table 1 presents the descriptive statistics for oil and gold future contracts. Average returns are negative and close to zero for both oil and gold contracts.

Business Review: (2020) 15(2):75-85 


\section{F. Shear}

Oil contracts' returns show volatility of more than $2 \%$ which is greater than volatility of gold returns. Distance of extreme values (minimum and maximum) further confirms this pattern. Skewness values from both markets indicate that returns are negatively skewed in both markets. Kurtosis values are quite higher for oil returns, which indicate that probability of extreme returns for oil futures is quite higher.

Gold future returns have also higher values of kurtosis, but they are quite

Table 1: Summary statistics

\begin{tabular}{cccccccc}
\hline & Mean & Std. Dev. & Skewness & Kurtosis & Min & Max & Obs \\
\hline \multicolumn{7}{c}{ Oil } \\
\hline Ret & -0.145 & 2.397 & -5.067 & 101.596 & -48.900 & 17.700 & 2299 \\
Spr & 1.785 & 1.842 & 3.658 & 27.046 & 0 & 24.123 & 2299 \\
\hline \multicolumn{7}{c}{ Gold } \\
\hline Ret & -0.078 & 0.78 & -0.199 & 8.909 & -5.132 & 6.167 & 2702 \\
Spr & 1.033 & 1.439 & 7.11 & 92.107 & 0 & 28.665 & 2702 \\
\hline
\end{tabular}

This table presents summary statistics for oil and gold future contracts. Ret represents returns and $S p r$ shows speculation ratio calculated by using formula in equation 2. Min, Max and Obs represents Minimum, Maximum, and number of observations, respectively.

lower in comparison to oil returns. Higher kurtosis values highlight the existence of fat tails for both returns series. Skewness and high kurtosis values (i.e., fat tails) of returns in both commodities indicate that returns do not follow normal distribution. Speculative activity is higher in oil market in comparison to gold market. Moreover, oil market exhibits more variations in speculative activity as well.

Figure $1 \mathrm{a}$ and $1 \mathrm{~b}$ show log returns for gold and oil contracts. Both return series show volatility clustering. Both markets exhibit volatility clustering, which makes applicability of ARCH model an appropriate choice for analysis. Moreover, graphs show that both series depict more volatility during ending period, which is year 2020 .

\subsection{Unit root test}

To test the stationarity of both series, the study uses Augmented Dicky Fuller (ADF) test of Dickey and Fuller (1979). Table 2 presents the results of the ADF test. The null hypothesis is that the series contain unit root, and the alternative hypothesis is that series does not contain unit root. Results indicate that null hypothesis is rejected for returns and speculation ratio of oil and gold future contracts. Thus, both series are stationary. 


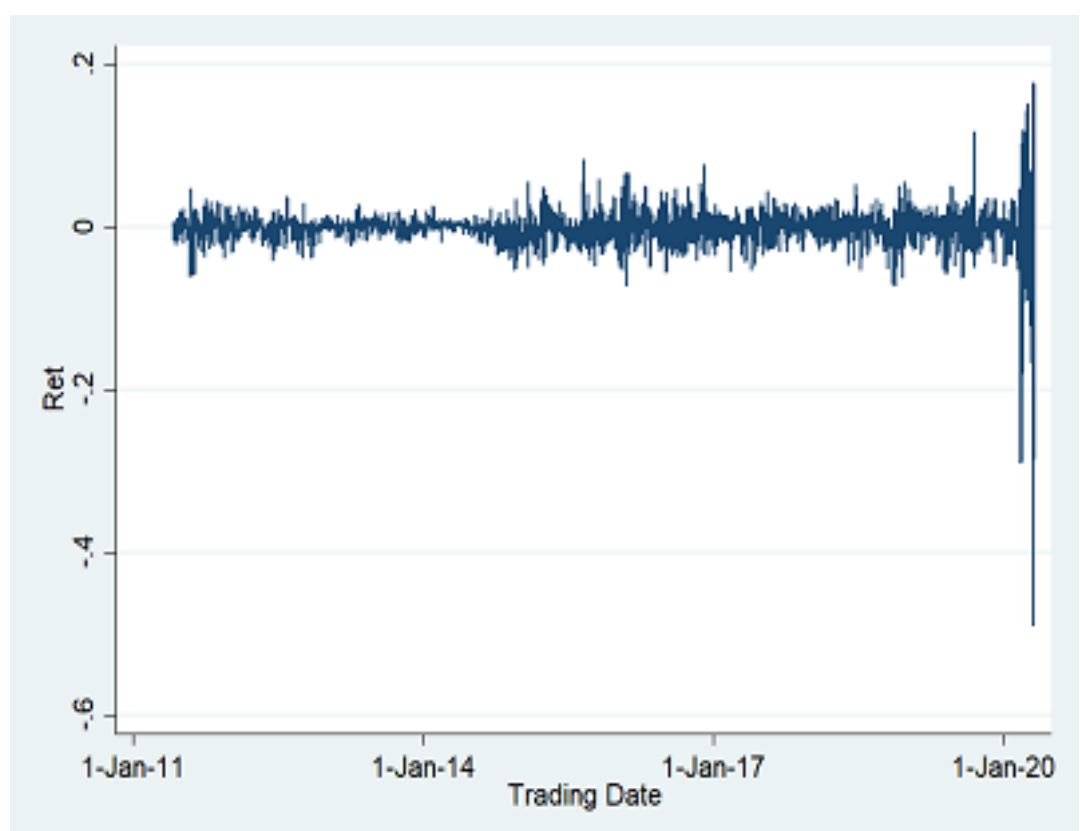

Figure 1a Gold future contracts: log returns

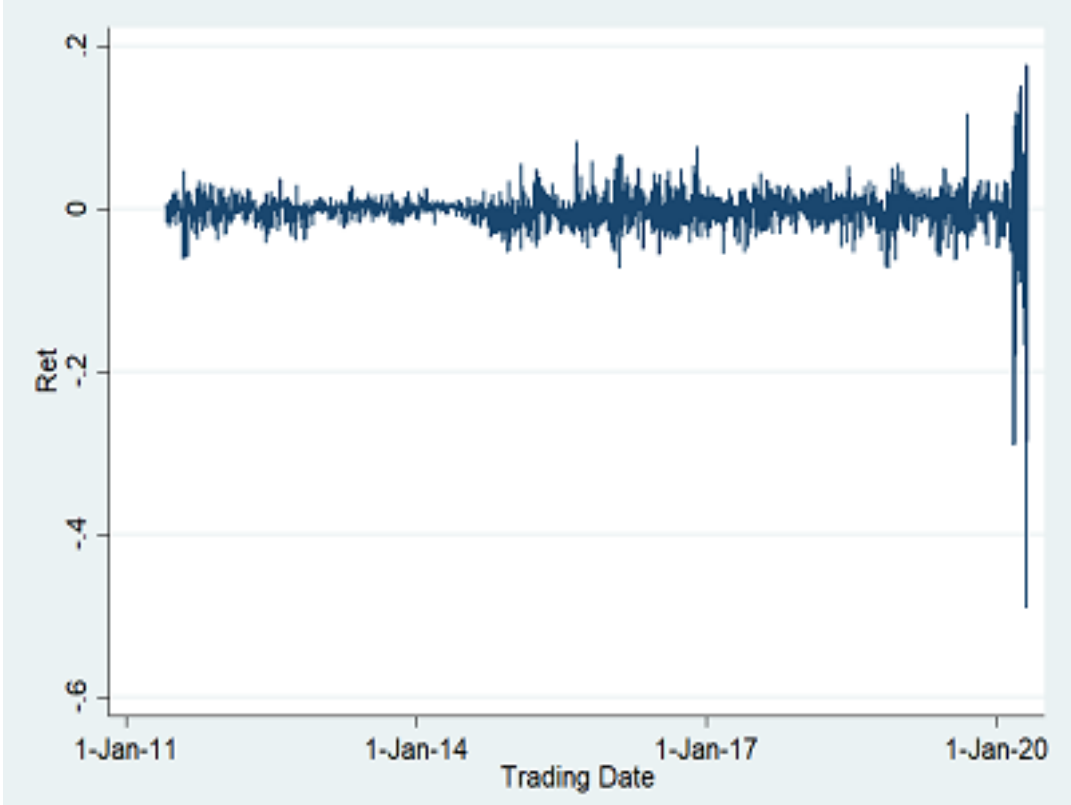

Figure 1b Oil future contracts: log returns 
Table 2: Augmented Dicky Fuller test

\begin{tabular}{lcc}
\hline & \multicolumn{2}{c}{ ADF test } \\
\hline & Ret & Spr \\
\hline Oil & $-18.842^{* * *}$ & $-12.284^{* * *}$ \\
Gold & $-20.659^{* * *}$ & $-7.987^{* * *}$ \\
\hline
\end{tabular}

Ret and Spr represents return and speculation ratio respectively. $* * *$ statistical significance at $1 \%$ level.

\subsection{LM Test}

Lagrange Multiplier (LM) test of (Engle 1982) is applied to test the presence of Autoregressive Conditional Heteroscedasticity (ARCH) effect in returns. The null hypothesis of no ARCH effect is tested against alternative hypothesis of ARCH effect. Table 3 presents results for the LM test. As evident from the table, the null hypothesis is overwhelmingly rejected for both returns series. Thus, it can be concluded that errors of both returns series show the presence of ARCH effect.

Table 3: LM test for Autoregressive Conditional Heteroskedasticity $(\mathrm{ARCH})$

\begin{tabular}{lcc}
\hline Returns & Lags & $\chi^{2}$ statistics \\
\hline Oil & 1 & $57.368^{* * *}$ \\
Gold & 1 & $127.666^{* * *}$ \\
\hline$* * *$ & statistical significance at $1 \%$ \\
level. $\chi^{2}$ statistics & represents Chi- \\
square statistics.
\end{tabular}

\subsection{EGARCH results}

Table 4 presents the results for EGARCH model of gold future contract returns. From the results of the mean equation, positive and significant impact of lag returns on current returns is evident. Moreover, returns of KSE negatively and significantly impact gold future contract returns. In variance equation, the negative value of $\gamma_{1}$ implies existence of negative leverage in the PMEX, which means that bad news has larger effect on volatility of gold futures than positive news. This finding is aligned with findings of Fakhfekh and Jeribi (2020). $\beta_{1}$, the coefficient of speculation ratio is positive and significant. It implies that speculative activity has positive impact on conditional volatility of returns. These findings are in line with the results of Bosch and Pradkhan (2015). These authors find destabilizing impact of speculation on returns of precious metals (i.e., Gold, silver, and palladium). The results of this study are also in line with the 
findings of Huchet and Fam (2016) who highlight the positive impact of speculation on returns' volatility for four agricultural commodities.

Table 5 presents results for oil future contract analysis. Similar to gold re-

Table 4: ARCH model results for GOLD future contracts

\begin{tabular}{|c|c|c|c|c|}
\hline & \multicolumn{4}{|c|}{ Mean Equation } \\
\hline & Coef. & Std. Err. & $\mathrm{z}$ & Prob \\
\hline$a_{0}$ & -0.068 & 0.011 & -6.200 & 0.000 \\
\hline$a_{1}$ & 0.045 & 0.015 & 2.870 & 0.004 \\
\hline \multirow[t]{2}{*}{$a_{2}$} & -0.021 & 0.012 & -1.870 & 0.061 \\
\hline & \multicolumn{4}{|c|}{ Variance } \\
\hline$\gamma_{0}$ & -1.603 & 0.057 & -27.660 & 0.000 \\
\hline$\beta_{1}$ & 0.660 & 0.030 & 21.900 & 0.000 \\
\hline$\gamma_{1}$ & -0.134 & 0.029 & -4.610 & 0.000 \\
\hline$\theta_{1}$ & 0.110 & 0.038 & 2.840 & 0.005 \\
\hline$\delta_{1}$ & -0.201 & 0.031 & -6.450 & 0.000 \\
\hline \multicolumn{5}{|c|}{$\begin{array}{l}\text { This table presents the results of EGARCH } \\
\text { model for Oil future contracts. } a_{0} \text { is con- } \\
\text { stant, } a_{1} \text { and } a_{2} \text { are coefficients of lag returns } \\
\text { and KSE returns, respectively, as described in } \\
\text { equation } 3 . \gamma_{0} \text { is constant's coefficient, } \gamma_{1} \text { is } \\
\text { leverage coefficient, } \theta_{1} \text { is coefficient for sym- } \\
\text { metric effect, } \delta_{1} \text { is EGARCH coefficient, and } \\
\beta_{1} \text { is coefficient of speculation ratio as illus- } \\
\text { trated in equation } 4 \text {. Z is Z-statistics, Prob is } \\
\text { probability and Std. Err. Stands for Standard } \\
\text { Errors. }\end{array}$} \\
\hline
\end{tabular}

sults, lag returns have positive and significant impact on oil returns. However, contrary to gold future returns, returns of KSE has positive impact on oil future returns. Variance equation models the relationship between conditional volatility of oil returns and speculation activity as measured by speculation ratio. Similar to previous results, oil future contracts also show negative leverage as $\gamma_{1}$ is negative and significant. Variable of interest i.e., speculation has positive and significant impact on oil future returns, which implies that speculation activity increases the return volatility. This finding is in contrast with findings of Manera et al (2016) who find negative and significant impact of speculative activity on return volatility for crude oil contracts in the US market. However, the findings of this study are in line with findings of Bohl et al (2018). These authors find positive impact of speculative activity on returns volatility for Chinese commodities. Findings from both of the markets i.e., oil and gold support the destabilizing hypothesis.

\section{Conclusion}

Motivated by the disagreement among empirical findings of literature about stabilizing or destabilizing role of speculative activity in future markets, this paper 
Table 5: ARCH model resutls for Oil future contracts

\begin{tabular}{ccccc}
\hline \multicolumn{5}{c}{ Mean Equation } \\
\hline & Coef. & Std. Err. & $\mathrm{z}$ & Prob \\
\hline$a_{0}$ & 0.037 & 0.021 & 1.750 & 0.080 \\
$a_{1}$ & 0.081 & 0.019 & 4.070 & 0.000 \\
$a_{2}$ & 0.041 & 0.022 & 1.830 & 0.067 \\
\hline \multicolumn{5}{c}{ Variance Equation } \\
\hline$\gamma_{0}$ & 0.003 & 0.006 & 0.420 & 0.673 \\
$\beta_{1}$ & 0.007 & 0.003 & 2.000 & 0.046 \\
$\gamma_{1}$ & -0.068 & 0.011 & -5.780 & 0.000 \\
$\theta_{1}$ & 0.126 & 0.018 & 6.850 & 0.000 \\
$\delta_{1}$ & 0.987 & 0.003 & 274.650 & 0.000 \\
\hline
\end{tabular}

This table presents the results of EGARCH model for Oil future contracts. $a_{0}$ is constant, $a_{1}$ and $a_{2}$ are coefficients of lag returns and KSE returns, respectively, as described in equation 3. $\gamma_{0}$ is constant's coefficient, $\gamma_{1}$ is leverage coefficient, $\theta_{1}$ is coefficient for symmetric effect, $\delta_{1}$ is EGARCH coefficient, and $\beta_{1}$ is coefficient of speculation ratio as illustrated in equation 4. $\mathrm{Z}$ is Z-statistics, Prob is probability and Std. Err. Stands for Standard Errors.

explores the above mentioned relationship for Pakistan Mercantile Exchange. PMEX has shown rapid growth since start of its trading in 2007. Two future contracts of PMEX i.e., oil and gold, which are among top 10 liquid contracts in PMEX are used.

Speculation activity is proxied by speculation ratio which is obtained by dividing trading volume over open interest. This ratio is quite extensively used in literature. To measure the influence of speculation ratio on returns volatility, this study uses EGARCH model. Two important findings emerge from this study. The first is that PMEX exhibits negative leverage, which means that bad news has more destabilizing effect. The second finding is that speculative activity has positive and significant impact on oil and gold future contracts in PMEX. This finding is in line with previous literature (Bohl et al 2018; Huchet and Fam 2016; Bosch and Pradkhan 2015; Du et al 2011) and supports the destabilizing hypothesis i.e. speculative activities destabilize the futures market.

These findings imply that regulators need to closely monitor speculation activities in the PMEX. However, a ban or any other restriction might be harmful to the evolution of the market at this nascent stage. Secondly, market participants, for instance hedgers might not be able to make profits due to welfare gains. Thirdly, PMEX might not be liquid enough to absorb large order flows due to financialization of commodity markets. Moreover, investors can expect more risky returns from the PMEX with an increase in speculative activity. Future studies can focus on the motives behind speculative activities in PMEX. 


\section{References}

Asteriou D, Hall S (2011) Applied econometrics: Palgrave macmillan

Bohl MT, Stephan PM (2012) Does futures speculation destabilize spot prices? new evidence for commodity markets. New Evidence for Commodity Markets (January 4, 2012)

Bohl MT, Sulewski C (2019) The impact of long-short speculators on the volatility of agricultural commodity futures prices. Journal of commodity markets 16:100,085

Bohl MT, Siklos PL, Wellenreuther C (2018) Speculative activity and returns volatility of chinese agricultural commodity futures. Journal of Asian Economics 54:69-91

Bollerslev T (1986) Generalized autoregressive conditional heteroskedasticity. Journal of econometrics 31(3):307-327

Bosch D, Pradkhan E (2015) The impact of speculation on precious metals futures markets. Resources Policy 44:118-134

Brunetti C, Buyuksahin B, Harris JH (2011) Speculators, prices and market volatility. Available at SSRN 1736737

Daigler RT, Wiley MK (1999) The impact of trader type on the futures volatility-volume relation. The Journal of Finance 54(6):2297-2316

Dickey DA, Fuller WA (1979) Distribution of the estimators for autoregressive time series with a unit root. Journal of the American statistical association 74(366a):427-431

Du X, Cindy LY, Hayes DJ (2011) Speculation and volatility spillover in the crude oil and agricultural commodity markets: A bayesian analysis. Energy Economics 33(3):497-503

Ederington L, Lee JH (2002) Who trades futures and how: Evidence from the heating oil futures market. The Journal of Business 75(2):353-373

Engle RF (1982) Autoregressive conditional heteroscedasticity with estimates of the variance of united kingdom inflation. Econometrica: Journal of the Econometric Society pp 9871007

Fakhfekh M, Jeribi A (2020) Volatility dynamics of crypto-currencies returns: Evidence from asymmetric and long memory garch models. Research in International Business and Finance 51:101,075

Garcia P, Leuthold RM, Zapata H (1986) Lead-lag relationships between trading volume and price variability: New evidence. The Journal of Futures Markets (1986-1998) 6(1):1

Huchet N, Fam PG (2016) The role of speculation in international futures markets on commodity prices. Research in International Business and Finance 37:49-65

Irwin SH, Yoshimaru S (1999) Managed futures, positive feedback trading, and futures price volatility. Journal of Futures Markets: Futures, Options, and Other Derivative Products 19(7):759-776

Kim A (2015) Does futures speculation destabilize commodity markets? Journal of Futures Markets 35(8):696-714

Manera M, Nicolini M, Vignati I (2016) Modelling futures price volatility in energy markets: Is there a role for financial speculation? Energy Economics 53:220-229

Nelson DB (1991) Conditional heteroskedasticity in asset returns: A new approach. Econometrica: Journal of the Econometric Society pp 347-370

Shear F, Butt H (2017) An analysis of the relationship between sovereign credit default swaps and the stock market of pakistan through handling outliers. Available at SSRN 2964820

Wellenreuther C, Voelzke J (2019) Speculation and volatilitya time-varying approach applied on chinese commodity futures markets. Journal of Futures Markets 39(4):405-417

Business Review: (2020) 15(2):75-85 